\title{
Litter mixing effect on decomposition rate and nutrient release: low quality leaves of coastal species
}

\author{
Lili Wei ${ }^{1}$ \\ ${ }^{1}$ Affiliation not available
}

October 5, 2021

\begin{abstract}
Coastal wetlands are among the most carbon-rich ecosystems in the world. Litter decomposition is a major process controlling soil carbon input. Litter mixing has shown a non-additive effect on the litter decomposition of terrestrial plants particularly of those species having contrasting litter quality. But the non-additive effect has been rarely tested in coastal plants which generally having low-quality litters. We selected three common mangrove species and one saltmarsh species, co-occurring in subtropical coasts, to test whether the non-additive effect occurs when the litters of these coastal species mixing together. We are also concerned whether the changes in the decomposition rate of litter will affect the nutrient contents in waters. A litter-bag experiment was carried out in a glasshouse with single and mixed leaf litters. A non-additive effect was observed in the litter mixtures of mangrove species Aegiceras corniculatum vs. Kandelia obovata (antagonistic) and A. corniculatum vs. Avicennia marina (synergistic). Whereas, the mixture of A. corniculatum (mangrove species) and Spartina alterniflora (saltmarsh species) showed an additive effect. The strength of the non-additive effect was unrelated to the initial trait dissimilarity of litters. Instead, the decomposition rate and mass remaining of litter mixtures were strongly related to the carbon concentrations in litters. Nutrient content in waters was dependent on the decomposition rate of litter mixtures but not on the initial nutrient concentrations in litters. Despite the behind mechanisms were not yet revealed by the current study, these findings have improved our understanding of the litter decomposition of coastal species and the consequent nutrient release.
\end{abstract}

Patrick Ndayambaje ${ }^{1,2}$, Lili Wei ${ }^{*}$, Tingfeng Zhang ${ }^{1,2}$, Lin Liu ${ }^{1}$, Xu Huang ${ }^{1}, \mathrm{Jie} \mathrm{Li}^{1,2}$, Shaohua Tian ${ }^{1,2}$, Yu Xin $^{1,2}$, Xuecong Sun ${ }^{1,2}$, Chaoxiang Liu $^{1}$

${ }^{1}$ Key Laboratory of Urban Pollutant Conversion, Institute of Urban Environment, Chinese Academy of Sciences, Xiamen 361021, China;

${ }^{2}$ University of Chinese Academy of Sciences, Beijing 100049, China.

*Corresponding author:l.l.wei@hotmail.com

ORCID id:https://orcid.org/0000-0002-9208-7240

\section{Keywords}

Aegiceras corniculatum, Avicennia marina, Community-weighted mean, Cordgrass, Kandelia obovata, Litter mixture, Non-additive effect, Trait dissimilarity

\section{Introduction}

Coastal wetlands are among the most important carbon storage ecosystems (Osland et al. 2018). Plant litters contribute greatly to the soil organic carbon of these wetlands through decomposition. Leaf litters in nature are usually mixed together and the litter decomposition rate of single species may not represent the real decomposition rate, because litter mixing could cause litter decomposition rates to be different from 
the mean rate of the component species, known as the non-additive effect (Lecerf et al. 2011; Handa et al. 2014). The alteration of litter decomposition due to the non-additive effect will alter the amount of $\mathrm{C}$ input to soils and the nutrient content in waters, and consequently impact the soil carbon stock and the nutrient purification capacity of the coastal wetlands.

The non-additive effect on litter decomposition has been observed in terrestrial plants, but has been rarely tested in coastal species. Kandelia obovata, Aegiceras corniculatum (black mangrove), and Avicennia marina (white mangrove) are among the most common species in subtropical mangrove forests. An alien salt marsh species Spartina alterniflora has emerged in some of these mangrove stands along the southeast coasts in China (Zhang et al. 2012). It is unknown whether the non-additive effect on litter decomposition occurs in these coastal communities.

Litter decomposition rate has been confirmed to be related to litter traits, including chemical traits, especially nitrogen $(\mathrm{N})$ or $\mathrm{C}: \mathrm{N}$ ratio and lignin concentrations, as well as some morphological traits such as leaf mass per area (LMA), specific leaf area (SLA) and leaf dry-matter content (LDMC) (Osono and Takeda 2004; Cornwell et al. 2008; Fortunel et al. 2009; Wickings et al. 2012; Coleman et al. 2020). Mass-ratio hypothesis and niche complementarity hypothesis are the main trait-based theories to explain the non-additive effect on litter decomposition (Finerty et al. 2016; García-Palacios et al. 2017). The mass-ratio hypothesis states that the dominant trait values have the greatest impact on ecological processes including litter decomposition, and the dominant trait values are reflected by the community-weighted mean of trait value (CWM) (Finerty et al. 2016; García-Palacios et al. 2017). In contrast, the niche complementarity hypothesis emphasizes the role of litter trait dissimilarity (Schimel and Hättenschwiler 2007; Berglund et al. 2013; Handa et al. 2014). Although both mass-ratio and niche complementarity hypotheses could explain litter decomposition and nutrient release (García-Palacios et al. 2017), their relative contributions varied with plant communities (Chapman and Koch 2007).

Unlike most land deciduous plants, coastal plants generally have low-quality litters as the consequence of adaptation to high salinity and nutrient-poor environments (Feller et al. 2003). In particular, their tissues are rich in the $\mathrm{C}$ concentrations and recalcitrant compounds such as phenolic compounds, condensed tannins, and lignin, which are highly resistant to decay (Kraus et al. 2003; Lin et al. 2006, 2007, 2010; Prescott 2010). Little is known whether the non-additive effect on decomposition occurs on these low-quality litters. In specific, this study aims to test: i) whether litter mixing affects litter decomposition rate and nutrient release; ii) if so, how trait dissimilarity and CWM of litter mixture control the non-additive effect of litter decomposition.

\section{Materials and methods}

We carried out a litter-bag experiment in a glasshouse in the Institute of Urban Environment, Chinese Academy of Science. The leaves were sampled from Quanzhou Bay Mangrove Reserve (24*57'24" N - 118*41'25" E), the south of Fujian, China (Hu et al. 2011). This site is characterized by an oceanic monsoon climate with a warm wet winter and hot rainy summer. The annual mean temperature is $20.4{ }^{*} \mathrm{C}$ and the average annual precipitation is $1095.4 \mathrm{~mm}$ (Lu et al. 2018). The dominant mangrove species encompassed Kandelia obovata, Aegiceras corniculatum, and Avicennia marina, with an alien saltmarsh species Spartina alterniflora emerged (Zhang et al. 2012). Three litter mixtures were set up based on species distributions in the field (Ndayambaje et al 2021): A. corniculatum vs. A. marina, A. corniculatum vs. K. obovata, and A. corniculatum vs. S. alterniflora. The soil was collected from the mangroves in Xiamen city: electronic conductivity (EC $\left.0.46+-0.05 \mathrm{~ms} \mathrm{~cm}^{-1}\right)$, organic matter $\left(0.32+-0.04 \mathrm{mg} \mathrm{g}^{-1}\right)$, carbon $\left(\mathrm{C} 20.09+-0.67 \mathrm{mg} \mathrm{g}^{-1}\right)$, total nitrogen (TN $2.02+-0.08 \mathrm{mg} \mathrm{g}^{-1}$ ), total phosphorus (TP $0.62+-0.03 \mathrm{mg} \mathrm{g}^{-1}$ ), sulphate (S $0.72+-0.07 \mathrm{mg}$ $\left.\mathrm{g}^{-1}\right)$, potassium $\left(\mathrm{K} 13.73+-3.33 \mathrm{mg} \mathrm{g}^{-1}\right)$, calcium $\left(\mathrm{Ca} 8.47+-2.39 \mathrm{mg} \mathrm{g}^{-1}\right)$, magnesium $(\mathrm{Mg} 9.96+-0.22$ $\left.\mathrm{mg} \mathrm{g}^{-1}\right)$ and $\mathrm{pH}(8.11+-0.06)$. 


\subsection{Experimental design}

Healthy green leaves were sampled from the trees of $K$. obovata, A. corniculatum, A. marina, and S. alterniflora in the same forest. Thus, all the leaves were exposed to similar climatic conditions, facilitated interspecies comparison of litter mass loss. After being taken to the laboratory, the leaves were gently washed and all dirt particles were then removed by using a soft brush followed by rinsing in distilled water. Five replicates were set up for each litter or litter mixture.

All leaf litter were air-dried to constant weight, $5 \mathrm{~g}$ of litter for each single species and $5 \mathrm{~g}$ of each litter mixture ( $2.5 \mathrm{~g}$ per species) were placed in each $75 \times 75 \mathrm{~mm}$ nylon bag with $1 \mathrm{~mm}^{2}$ mesh size. There were 40 bags in total, including 15 bags of litter mixture (3 pairs) and 25 for single species ( 5 single species). All the litter bags were placed on the top of the soil in the plastic containers, all the containers $(500 \mathrm{ml})$ consisted of $200 \mathrm{~g}$ soil and $200 \mathrm{ml}$ water. Based on the previous observation that the decomposition of mangrove leaves generally becomes slow and steady after 7 weeks (Chanda et al. 2016), the duration of 90 days is often representing a short-term decomposition experiment (Keuskamp et al. 2013).

\subsection{Element analysis}

After 90 days of decomposition, litter and water were collected to the laboratory for mass and nutrient analyses. The water on the soil surface was collected with a syringe and then stored in a polyethylene bottle. Litters were determined $\mathrm{C}$ and $\mathrm{N}$ concentrations with an elemental analyzer (Vario MAX, Vario MACRO, Germany Elementar) after being grounded through 60 mesh sieves. Phosphorus (P) in litters was quantified with an ICP-OES (Inductively Coupled Plasma Optical Emission Spectrometer, Optima 7000DV, PerkinElmer USA) after being digested with nitric and perchloric acid. The ammonium-nitrogen $\left(\mathrm{NH}_{4}-\mathrm{N}\right)$, nitrate-nitrogen $\left(\mathrm{NO}_{3}-\mathrm{N}\right)$, and nitrite-nitrogen $\left(\mathrm{NO}_{2}-\mathrm{N}\right)$ were quantified by an ultraviolet spectrophotometer (UV6100, mapada instrument, China) following the standard methods (Wei et al. 2002). Digestion of the water by alkaline potassium persulfate and potassium persulfate were carried out after filtration of the water sample, and then the total $\mathrm{N}$ and total $\mathrm{P}$ were determined respectively according to the standard methods (Wei et al. 2002), $\mathrm{NH}_{4}-\mathrm{N}, \mathrm{NO}_{3}-\mathrm{N}$, and $\mathrm{NO}_{2}-\mathrm{N}$ then analyzed by an ultraviolet spectrophotometer (UV6100, mapada instruments, China). The condensed tannin of the leaves was also determined before the decomposition experiment was conducted. The total condensed tannin was the sum of the extractable, protein-bound, and fibre-bound concentrations. The extraction process was followed by the method of Lin et al. (2007).

\subsection{Calculation}

The litter mass loss was calculated by comparing the initial mass and the mass after decomposition. The initial mass remaining after decomposition was calculated based on the following formula (Wu et al., 2013):

$$
X_{r}=\frac{X_{i}}{X_{t}} \times 100
$$

Where $\mathrm{X}_{\mathrm{r}}$ is the percentage (\%) of mass remaining after decomposition, $\mathrm{X}_{\mathrm{i}}$ is the initial litter mass, $\mathrm{X}_{\mathrm{t}}$ is the mass of the remained litter in the litter bags after a given time period ( $\mathrm{t}$ ) of decomposition.

The decomposition rate $(\mathrm{k})$ was calculated by exponential decay model, the litter mass remaining after decomposition and initial litter mass:

$$
\frac{X_{t}}{X_{i}}={ }^{-k t}
$$

Where $\mathrm{k}$ is the decomposition rate coefficient; $\mathrm{t}$ is the time duration of decomposition. 
The percentage of the initial litter nutrient remaining $\left(\mathrm{N}_{\mathrm{r}}\right)$ during decomposition was calculated by the following equation (Zhang et al., 2014):

$$
N_{r}=\left(X_{t} \times\left[N_{t}\right]+X_{i} \times\left[X_{i}\right]\right) \times 100
$$

We also calculated the expected rate of the litter mixture after decomposition using the following formula:

$$
X_{\exp }=\left(\frac{X_{i 1}}{X_{i 1}+X_{i 2}} \times X_{r_{1}}+\frac{X_{i 2}}{X_{i 1}+X_{i 2}} \times X_{r_{2}}\right) \times 100
$$

Where $\mathrm{X}_{\text {exp }}$ is the percentage of the expected mass remaining (MR) after decomposition, $\mathrm{X}_{1}$ and $\mathrm{X}_{2}$ are the initial dry masses in single species which was $2.5 \mathrm{~g}$, and $\mathrm{X}_{\mathrm{r} 1}$ and $\mathrm{X}_{\mathrm{r} 2}$ are the mass remaining from the single decomposition species. The effect strength was calculated by the difference between the observed mass remaining (\%) and the expected mass remaining (\%) (O-E): additive (no significant difference between observed and expected values), synergistic non-additive (negative value, meaning an acceleration of litter decomposition), antagonistic non-additive (positive value, meaning a deceleration of litter decomposition) (Lecerf et al., 2011).

The community-weighted mean value of traits (CWM) was calculated as the mean value of each species in the mixture because the two litters mixed as 1: 1 of mass in this study (Roscher et al., 2018).

\subsection{Statistical analysis}

Statistical analysis was performed with IBM SPSS Statistics 23. All data were removed outlier and checked for the normal distribution and homogeneity of variances before the statistical analysis was carried out. Oneway ANOVA was used to detect the differences in decomposition rate and water nutrient content among litters, as well as in trait dissimilarity and CWM among each trait. The differences in mass remaining and water nutrient content between the observed and the expected values were analyzed by an independent t-test. The variation of the difference in mass remaining between the observed and the expected values from zero was detected by one-sample t-test analysis. The linear correlations of decomposition rate or mass remaining with leaf trait dissimilarity or CWM were assessed through the correlation process. This process was also used to identify the correlation between water nutrient contents and leaf nutrient concentrations.

\section{Result}

Non-additive effects on litter decomposition were observed of the litter mixtures composed of mangrove species. The water nutrient content, the initial trait dissimilarity, and the CWM of litter mixtures varied with species composition.

\subsection{Decomposition rate $(\mathrm{k})$ and mass remaining}

Non-additive effects on litter decomposition were detected in the litter mixtures composed of mangrove species, but not in the mixture of A. corniculatum vs. S. alterniflora (Fig. 1ab). The observed mass remaining of the mixture of $A$. corniculatum vs. $K$ obovata was substantially higher than the expected value $(P<0.01)$, whereas the observed mass remaining of the mixture of $A$. corniculatum vs. A. marina was lower than the expected one $(P=0.04)$, and the mixture of $A$. corniculatum vs. S. alterniflora did not show a significant difference between the observed and the expected values $(P=0.21$; Fig. $1 \mathrm{~b})$.

The strength and the direction of the non-additive effect were indicated by the deviation of the non-additive effect from zero (Fig. 2). The mixture of $A$. corniculatum vs. K. obovata performed a positive and strongest non-additive effect than the other mixtures $(P<0.01)$. Whereas, A. corniculatum vs. A. marina showed a 
negative non-additive effect $(P=0.04)$. The mixture of $A$. corniculatum vs. $S$. alterniflora did not show a non-additive effect $(P=0.31)$.

\subsection{Water nutrient content after decomposition}

The single litter of $A$. corniculatum led to lower water content in $\mathrm{NH}_{4}-\mathrm{N}(P<0.001)$ than the litters mixed with the other species (Fig. 3a), but did not have differences in total $\mathrm{N}(P>0.05), \mathrm{PO}_{3}-\mathrm{P}(P>0.10)$ and total $\mathrm{P}(P>0.10)$ from the mixed litters (Fig. 3ab). The single litter of $K$. obovata led to lower water content in $\mathrm{NH}_{4}-\mathrm{N}(P=0.02)$ than the mixed litter (Fig. 3a), but no differences in the other nutrients $(P>$ 0.10; Fig. 3ab). The single litter of $A$. marina led to higher water content in all tested nutrients than the mixed litters $\left(P<0.01\right.$ for $\mathrm{NH}_{4}-\mathrm{N}$, total $\mathrm{N}$, and $\mathrm{PO}_{3}-\mathrm{P}, P=0.01$ for total $\mathrm{P}$; Fig. 3ab). The single litter of $S$. alterniflora showed no differences in all the water nutrients from the mixed litter $(P>0.10$; Fig. 3ab).

Comparing the three litter mixtures, A. corniculatum vs. $K$. obovata were lower in all the water nutrients than corniculatum vs. A. marina $\left(P=0.01\right.$ for $\mathrm{NH}_{4}-\mathrm{N} ; P=0.03$ for $\mathrm{N} ; P=0.71$ for $\mathrm{PO}_{3}-\mathrm{P} ; P=0.009$ for $\mathrm{P})$ and $A$. corniculatum vs. $S$. alterniflora $\left(P=0.11\right.$ for $\mathrm{NH}_{4}-\mathrm{N} ; P=0.13$ for $\mathrm{N} ; P=0.95$ for $\mathrm{PO}_{3}-\mathrm{P} ; P=$ 0.59 for P) (Fig. 3).

\subsection{Trait dissimilarity and CWM of litter mixtures}

The litter mixture of $A$. corniculatum vs. K. obovata had lower dissimilarity in leaf $\mathrm{N}$ and $\mathrm{P}$, and greater in LDMC than the other litter mixtures (Fig. 4bce). The litter mixture of $A$. corniculatum vs. A. marina showed greater dissimilarity in leaf $\mathrm{C}$ and $\mathrm{P}$ or LDMC than the others (Fig. 4a, c), while A. corniculatum vs. S. alterniflora had lower dissimilarity in leaf C and LDMC but greater in leaf N and SLA than the others (Fig. 4abde).

Among the litter mixtures, $A$. corniculatum vs. $K$. obovata had the highest leaf $\mathrm{C}$ but lowest leaf nutrients (N and $\mathrm{P}), A$. corniculatum vs. A. marina had the highest leaf nutrients and SLA but the lowest leaf C: N and A. corniculatum vs. S. alterniflora had lower leaf nutrients and SLA but higher LDMC than the others (Fig. 5). Among the single litters, A. corniculatum $\left(100.59 \pm 25.47 \mathrm{mg} \mathrm{g}^{-1}\right)$ and K. obovata $(162.78 \pm 8.00$ $\left.\mathrm{mg} \mathrm{g}^{-1}\right)$ had higher concentration of condensed tannin than A. marina $(1.93 \pm 0.33)$ and S. alterniflora $(3.21$ $\left.\pm 0.68 \mathrm{mg} \mathrm{g}^{-1}\right)$.

\section{Discussion}

This study revealed that non-additive effect on decomposition occurred in the litter mixtures composed of mangrove species. The CWM of leaf C instead of trait dissimilarity was the key factor controlling the litter decomposition rate of litter mixtures. The water nutrient content resulted from litter decomposition was more likely controlled by litter decomposition rate rather than by the initial nutrient concentrations in litters.

\subsection{Mixing effect differing among litter mixtures}

These three mangrove species are among the widest spread species in subtropical mangrove forests (Yang et al. 2014). Surprisingly, we did not find any study to examine the non-additive effect on litter decomposition of these mangroves. Our study revealed that the non-additive effect occurred in the litter mixtures composed of mangrove species with an antagonistic effect on the litter mixture of $A$. corniculatum vs. K. obovata while a synergistic effect on $A$. corniculatum vs. A. marina. If these results are extended to community scale, it is expecting that the stand composed of $A$. corniculatum and $K$. obovata would have slower leaf litter decomposition rate than the stand dominated by A. corniculatum and A. marina. 
The litters mixed with $A$. corniculatum and S. alterniflora showed a weak non-additive effect. This is consistent with the result of a study in Georgia, USA, where the litters of $S$. alterniflora mixed with the other saltmarsh species Juncus roemerianus and Quercus virginiana did not show impact on the decomposition rates of the mixed litters (Treplin et al. 2013).

\subsection{Relationships of trait dissimilarity and CWM to the decomposition rate}

A strong non-additive effect generally occurs in a litter mixture with divergent traits (Kuebbing and Bradford 2019). For example, deciduous subordinates significantly impacted litter decomposition in an evergreendominated forest where the trait values were contrasting between deciduous and evergreen species (Guo et al. 2020). However, we found no the relation of trait dissimilarity with the litter decomposition and the strength of non-additive effect. Instead, the CWM of litter C was related to the decomposition rate of litter mixtures in our study (Fig. 7). These findings agreed with the results derived from European tree species. There was no significant relationship between the decomposition rate and the litter trait dissimilarity of 28 litter mixtures (Frainer et al. 2015), but the trait CWM exerted the strongest effect on the mass loss of the litter mixtures in another study that the litter mixtures were derived from 14 European tree species (Finerty et al. 2016).

Trait CWM is related to mass-ratio hypothesis and trait dissimilarity related to niche complementarity hypothesis (Handa et al. 2014; Finerty et al. 2016; García-Palacios et al. 2017). The core point of these two mechanistic hypotheses is the interaction between litters (Tardif and Shipley 2013; Handa et al. 2014; Finerty et al. 2016; García-Palacios et al. 2017). Mass-ratio hypothesis proposes that there is no interaction between litters, or the positive and negative interactions cancel out each other (Tardif and Shipley 2013). While niche complementarity hypothesis emphasizes a positive interaction between litters (Schimel and Hättenschwiler 2007; Berglund et al. 2013; Handa et al. 2014). Although we did not directly examine the interactions between litters, the strong correlation of the trait CWM and the decomposition rate indicated a non-interaction between litters. This is consistent with the weak interaction between these alive species in our previous study (Ndayambaje et al. 2021).

Among litter mixtures, A. corniculatum vs. $K$. obovata had the highest CWM of leaf C, and the strongest non-additive effect but the lowest rate of litter decomposition (Fig. 6). The CWM of leaf C of $A$. corniculatum vs. A. marina and A. corniculatum vs. S. alterniflora were similar, but A. corniculatum vs. A. marina had higher CWM of leaf $\mathrm{N}$ and $\mathrm{P}$ and concurrently a faster decomposition rate than $A$. corniculatum vs. $S$. alterniflora (Fig. 6). Taken together, these results indicated that the $\mathrm{C}$ concentration of litters was a key trait strongly controlling litter decomposition rate, with adjusted by the $\mathrm{N}$ and $\mathrm{P}$ concentrations in litters.

The litters of mangrove species are generally characterized by low-quality, such as high in $\mathrm{C}$ and phenolics (Kraus et al. 2003; Lin et al. 2006, 2007, 2010; Prescott 2010). Lignin-derived phenols can be lost at a lower rate during decomposition than the total neutral sugars and the bulk organic $\mathrm{C}$ (Marchand et al. 2005). Condensed tannins tend to bind more strongly to protein than to fibre, which enable to sequester nitrogenous materials and conserved $\mathrm{N}$ in leaf litter rather than providing to soil microbe, such mechanism could retard litter decomposition rate (Lin et al. 2006; Zhou et al. 2012). Among the tested coastal species, $A$. corniculatum and $K$. obovata had profoundly greater concentrations in leaf condensed tannin than $A$. marina and S. alterniflora. Some other studies also found that A. corniculatum had highest total polyphenols, and A. marina had very low or even undetectable levels in total polyphenols (Zhou et al. 2010; Wang et al. 2014). These observations provide additional support to explain why the litter mixture of $A$. corniculatum vs. $K$. obovata showed lower decomposition rate than $A$. corniculatum vs. S. alterniflora and A. corniculatum vs. A. marina. 


\subsection{Potential factors control nutrient release}

Nutrient release during litter decomposition could be a nutrient source for the water column. There are accumulated studies that explored the effect of litter decomposition on water quality (McClaugherty et al. 1985; Zhai et al. 2019), but little is known about the effect of litter mixing on the water nutrient contents through decomposition. Our results indicated that the water nutrient content was mainly controlled by litter decomposition rate but not the initial nutrient concentrations in litters.

The effect of litter on nutrient release during decomposition can be related directly and indirectly to the initial litter quality and the decomposition rate (Liu et al. 2010). However, previous studies have paid the most attention to the effect of litter quality. In contrast, we did not find the relationship between the water nutrient content and the nutrient concentration in leaves (Fig. 7). We further confirmed that the nutrients released into waters were controlled by the decomposition rate of litter mixtures, indicated by the strongly positive correlations between water nutrient contents and litter decomposition rate (Fig. 8). Although such relations have been confirmed in some aquatic plants (Wu et al. 2017) and algae (Cao et al. 2015), these studies have not considered litter mixtures.

\section{Conclusion}

This study revealed that litter mixing affected litter decomposition rate and litter nutrient release in both synergistic and antagonistic patterns. The decomposition rate of litter mixture was strongly related to the CWM of litter $\mathrm{C}$, and the water nutrient contents were likely controlled by litter decomposition rate.

This study included only four species and three litter mixtures, but the four species are widely distributed in subtropical coasts. Our findings may be helpful in understanding the effect of plant composition on coastal ecosystem functioning. The mangrove species $A$. corniculatum and $K$. obovata living together would be beneficial to soil $\mathrm{C}$ accumulation and water purification due to slow litter decomposition.

\section{Acknowledgments}

This study was funded by the National Natural Science Foundation of China (31570400).

\section{Author Contribution}

LW conceived the ideas. LW and PN wrote this manuscript. All authors contributed to the improvement of this manuscript and gave final approval for publication.

\section{References}

Berglund, S.L., Ågren, G.I., Ekblad, A., 2013. Carbon and nitrogen transfer in leaf litter mixtures. Soil Biology and Biochemistry, 57, 341-348. https://doi.org/10.1016/j.soilbio.2012.09.015

Cao, X., Han, R., Zhang, T., Wang, G., Wei, H., Ma, Y., Ji, F., Ma, J., 2015. Decomposition of aquatic plants during winter and its influence on water quality. J. Agro-Environ. SCI 34, 361-369. (In Chinese)

Chanda, A., Akhand, A., Manna, S., Das, S., Mukhopadhyay, A., Das, I., .. Dadhwal, V.K., 2016. Mangrove associates versus true mangroves: a comparative analysis of leaf litter decomposition in Sundarban. Wetlands Ecology and Management, 24, 293-315. https://doi:10.1007/s11273-015-9456-9

Chapman, S.K., Koch, G.W., 2007. What type of diversity yields synergy during mixed litter decomposition in a natural forest ecosystem?. Plant and soil, 299, 153-162. https://doi.org/10.1007/s11104-007-9372-8

Coleman, B.R., Martin, A.R., Thevathasan, N.V., Gordon, A.M., Isaac, M.E., 2020. Leaf trait variation and decomposition in short-rotation woody biomass crops under agroforestry management. Agriculture, Ecosystems \& Environment, 298, 106971. doi: 10.1016/j.agee.2020.106971 
Cornwell, W.K., Cornelissen, J.H., Amatangelo, K., Dorrepaal, E., Eviner, V.T., Godoy, O., ... Westoby, M., 2008. Plant species traits are the predominant control on litter decomposition rates within biomes worldwide. Ecology letters, 11, 1065-1071. https://doi.org/10.1111/j.1461-0248.2008.01219.x

Finerty, G.E., de Bello, F., Bílá, K., Berg, M.P., Dias, A.T., Pezzatti, G.B., Moretti, M., 2016. Exotic or not, leaf trait dissimilarity modulates the effect of dominant species on mixed litter decomposition. Journal of Ecology, 104, 1400-1409. https://doi.org/10.1111/1365-2745.12602

Fortunel, C., Garnier, E., Joffre, R., Kazakou, E., Quested, H., Grigulis, K., .. Zarovali, M., 2009. Leaf traits capture the effects of land use changes and climate on litter decomposability of grasslands across Europe. Ecology, 90, 598-611. https://doi.org/10.1890/08-0418.1

Frainer, A., Moretti, M.S., Xu, W., Gessner, M.O., 2015. No evidence for leaf-trait dissimilarity effects on litter decomposition, fungal decomposers, and nutrient dynamics. Ecology, 96, 550-561. https://doi.org/10.1890/14-1151.1

Garcia-Palacios, P., Shaw, E.A., Wall, D.H., Hattenschwiler, S., 2017. Contrasting mass-ratio vs. niche complementarity effects on litter $\mathrm{C}$ and $\mathrm{N}$ loss during decomposition along a regional climatic gradient. Journal of Ecology, 105, 968-978. https://doi.org/10.1111/1365-2745.12730

Guo, C., Cornelissen, J.H., Tuo, B., Ci, H., Yan, E.R., 2020. Non-negligible contribution of subordinates in community-level litter decomposition: Deciduous trees in an evergreen world. Journal of Ecology, 108, 1713-1724. https://doi.org/10.1111/1365-2745.13341

Handa, I.T., Aerts, R., Berendse, F., Berg, M.P., Bruder, A., Butenschoen, O., .. Hattenschwiler, S., 2014. Consequences of biodiversity loss for litter decomposition across biomes. Nature, 509, 218-221. doi: $10.1038 /$ nature 13247

Hu, G., Yu, R., Zhao, J., Chen, L., 2011. Distribution and enrichment of acid-leachable heavy metals in the intertidal sediments from Quanzhou Bay, southeast coast of China. Environmental monitoring and assessment, 173, 107-116. https://doi.org/10.1007/s10661-010-1374-y

Keuskamp, J.A., Dingemans, B.J., Lehtinen, T., Sarneel, J.M., Hefting, M.M. (2013). Tea Bag Index: a novel approach to collect uniform decomposition data across ecosystems. Methods in Ecology and Evolution, 4(11), 1070-1075. https://doi.org/10.1111/2041-210X.12097

Kraus, T.E., Dahlgren, R.A., Zasoski, R.J., 2003. Tannins in nutrient dynamics of forest ecosystems-a review. Plant and soil, 256, 41-66. https://doi.org/10.1023/a:1026206511084

Kuebbing, S.E., Bradford, M.A., 2019. The potential for mass ratio and trait divergence effects to explain idiosyncratic impacts of non-native invasive plants on carbon mineralization of decomposing leaf litter. Functional Ecology, 33, 1156-1171. https://doi.org/10.1111/1365-2435.13316

Lecerf, A., Marie, G., Kominoski, J.S., LeRoy, C.J., Bernadet, C., Swan, C.M., 2011. Incubation time, functional litter diversity, and habitat characteristics predict litter-mixing effects on decomposition. Ecology, 92, 160-169. https://doi.org/10.1890/10-0315.1

Lin, Y.M., Liu, J.W., Xiang, P., Lin, P., Ding, Z.H., Sternberg, L.D.S.L., 2007. Tannins and nitrogen dynamics in mangrove leaves at different age and decay stages (Jiulong River Estuary, China). Hydrobiologia, 583, 285-295. doi: 10.1007/s10750-006-0568-3

Lin, Y.M., Liu, J.W., Xiang, P., Lin, P., Ye, G.F., Da Sternberg, L.S.L., 2006. Tannin dynamics of propagules and leaves of Kandelia candel and Bruguiera gymnorrhiza in the Jiulong River Estuary, Fujian, China. Biogeochemistry, 78, 343-359. https://doi.org/10.1007/s10533-005-4427-5

Lin, Y.M., Liu, X.W., Zhang, H., Fan, H.Q., Lin, G.H., 2010. Nutrient conservation strategies of a mangrove species Rhizophora stylosaunder nutrient limitation. Plant and soil, 326, 469-479. doi: 10.1007/s11104-009$0026-\mathrm{x}$ 
Liu, P., Huang, J., Sun, O.J., Han, X., 2010. Litter decomposition and nutrient release as affected by soil nitrogen availability and litter quality in a semiarid grassland ecosystem. Oecologia, 162, 771-780. https://doi.org/10.1007/s00442-009-1506-7

Lu, C., Liu, J., Jia, M., Liu, M., Man, W., Fu, W., Zhong, L., Lin, X., Su, Y., Gao, Y., 2018. Dynamic analysis of mangrove forests based on an optimal segmentation scale model and multi-seasonal images in Quanzhou Bay, China. Remote Sensing, 10, 2020. https://doi.org/10.3390/rs10122020

Marchand, C., Disnar, J.R., Lallier-Verges, E., Lottier, N., 2005. Early diagenesis of carbohydrates and lignin in mangrove sediments subject to variable redox conditions (French Guiana). Geochimica et Cosmochimica Acta, 69, 131-142. https://doi.org/10.1016/j.gca.2004.06.016

McClaugherty, C.A., Pastor, J., Aber, J.D., Melillo, J.M., 1985. Forest litter decomposition in relation to soil nitrogen dynamics and litter quality. Ecology, 66, 266-275. https://doi.org/10.2307/1941327

Ndayambaje, P., Wei, L., Zhang, T., Li, Y., Liu, L., Huang, X., Liu, C., 2021. Niche separation and weak interactions in the high tidal zone of saltmarsh-mangrove mixing communities. Ecology and Evolution, 11, 3871-3883. https://doi.org/10.1002/ece3.7263

Osono, T., Takeda, H., 2004. Accumulation and release of nitrogen and phosphorus in relation to lignin decomposition in leaf litter of 14 tree species. Ecological Research, 19, 593-602. https://doi.org/10.1111/j.14401703.2004.00675.x

Prescott, C.E., 2010. Litter decomposition: what controls it and how can we alter it to sequester more carbon in forest soils?. Biogeochemistry, 101, 133-149. https://doi.org/10.1007/s10533-010-9439-0

Roscher, C., Schumacher, J., Gubsch, M., Lipowsky, A., Weigelt, A., Buchmann, N., .. Schmid, B., 2018. Interspecific trait differences rather than intraspecific trait variation increase the extent and filling of community trait space with increasing plant diversity in experimental grasslands. Perspectives in Plant Ecology, Evolution and Systematics, 33, 42-50. doi: 10.1016/j.ppees.2018.05.001

Schimel, J.P., Hattenschwiler, S., 2007. Nitrogen transfer between decomposing leaves of different N status. Soil Biology and Biochemistry, 39, 1428-1436. doi: 10.1016/j.soilbio.2006.12.037

Tardif, A., Shipley, B., 2013. Using the biomass-ratio and idiosyncratic hypotheses to predict mixed-species litter decomposition. Annals of Botany, 111, 135-141. https://doi.org/10.1093/aob/mcs241

Treplin, M., Pennings, S.C., Zimmer, M., 2013. Decomposition of leaf litter in a US saltmarsh is driven by dominant species, not species complementarity. Wetlands, 33, 83-89. https://doi.org/10.1007/s13157-0120353-1

Wang, Y., Zhu, H., Tam, N.F.Y., 2014. Polyphenols, tannins and antioxidant activities of eight true mangrove plant species in South China. Plant and soil, 374, 549-563. https://doi.org/10.1007/s11104-013-1912-9

Wei, F.S., Qi, W. Q., Sun, Z.G., Huang, Y.R., Shen, Y.W., 2002. Water and wastewater monitoring and analysis method. China Environmental Science Press, Beijing, 211-284. (In Chinese)

Wickings, K., Grandy, A.S., Reed, S.C., Cleveland, C.C., 2012. The origin of litter chemical complexity during decomposition. Ecology letters, 15, 1180-1188. https://doi.org/10.1111/j.1461-0248.2012.01837.x

Wu, D., Li, T., Wan, S., 2013. Time and litter species composition affect litter-mixing effects on decomposition rates. Plant and soil, 371, 355-366. doi:10.1007/s11104-013-1697-x

Wu, S., He, S., Huang, J., Gu, J., Zhou, W., Gao, L., 2017. Decomposition of emergent aquatic plant (cattail) litter under different conditions and the influence on water quality. Water, Air, \& Soil Pollution, 228, 70. https://doi.org/10.1007/s11270-017-3257-0

Yang, J., Gao, J., Liu, B., Zhang, W., 2014. Sediment deposits and organic carbon sequestration along mangrove coasts of the Leizhou Peninsula, southern China. Estuarine, Coastal and Shelf Science, 136, 3-10. 
https://doi.org/10.1016/j.ecss.2013.11.020

Zhai, J., Cong, L., Yan, G., Wu, Y., Liu, J., Wang, Y., ... Zhang, M., 2019. Influence of fungi and bag mesh size on litter decomposition and water quality. Environmental Science and Pollution Research, 26, 18304-18315. doi: 10.1007/s11356-019-04988-4

Zhang, C., Li, S., Zhang, L., Xin, X., Liu, X., 2014. Litter mixing significantly affects decomposition in the Hulun Buir meadow steppe of Inner Mongolia, China. Journal of Plant Ecology, 7, 56-67. https://doi.org/10.1093/jpe/rtt022

Zhang, Y., Huang, G., Wang, W., Chen, L., Lin, G., 2012. Interactions between mangroves and exotic Spartina in an anthropogenically disturbed estuary in southern China. Ecology, 93, 588-597. https://doi.org/10.1890/11-1302.1

Zhou, H.C., Tam, N.F.Y., Lin, Y.M., Wei, S.D., Li, Y.Y., 2012. Changes of condensed tannins during decomposition of leaves of Kandelia obovata in a subtropical mangrove swamp in China. Soil Biology and Biochemistry, 44, 113-121. https://doi.org/10.1016/j.soilbio.2011.09.015

Zhou, H.C., Wei, S.D., Zeng, Q., Zhang, L.H., Tam, N.F.Y., Lin, Y.M., 2010. Nutrient and caloric dynamics in Avicennia marina leaves at different developmental and decay stages in Zhangjiang River Estuary, China. Estuarine, Coastal and Shelf Science, 87, 21-26. https://doi.org/10.1016/j.ecss.2009.12.005 